\title{
Seeing in Section: \\ The practice of photogrammatic drawing
}

\author{
Shelley F. Martin
}

\section{The photogram as material drawing}

The science of photogrammetry accesses the space of photographs for the measurement, translation and production of data about an object or environment that has been stilled by a camera, and in doing so indirectly senses its qualities. This translation of the photographic image distills multiple reference points to estimate and map the three-dimensional qualities of objects, surfaces, and terrains. Just as principles of photogrammetry mine geometric properties from photographic records and project them as formal gestures, the photogram's direct transposition of a three-dimensional object onto a surface produces a field of inquiry rich in spatial consequence by examining light as a tectonic object. Yet the photogram does not merely record the object, it also transforms the object.

Laszlo Moholy-Nagy's initial photographic material practice of recording the form of light revealed a surface constructed solely by means of drawing. Moholy-Nagy saw photography as an act that inscribed both tangible and intangible qualities of light, surface, profile, and depths. Seeking to "... deal more with the
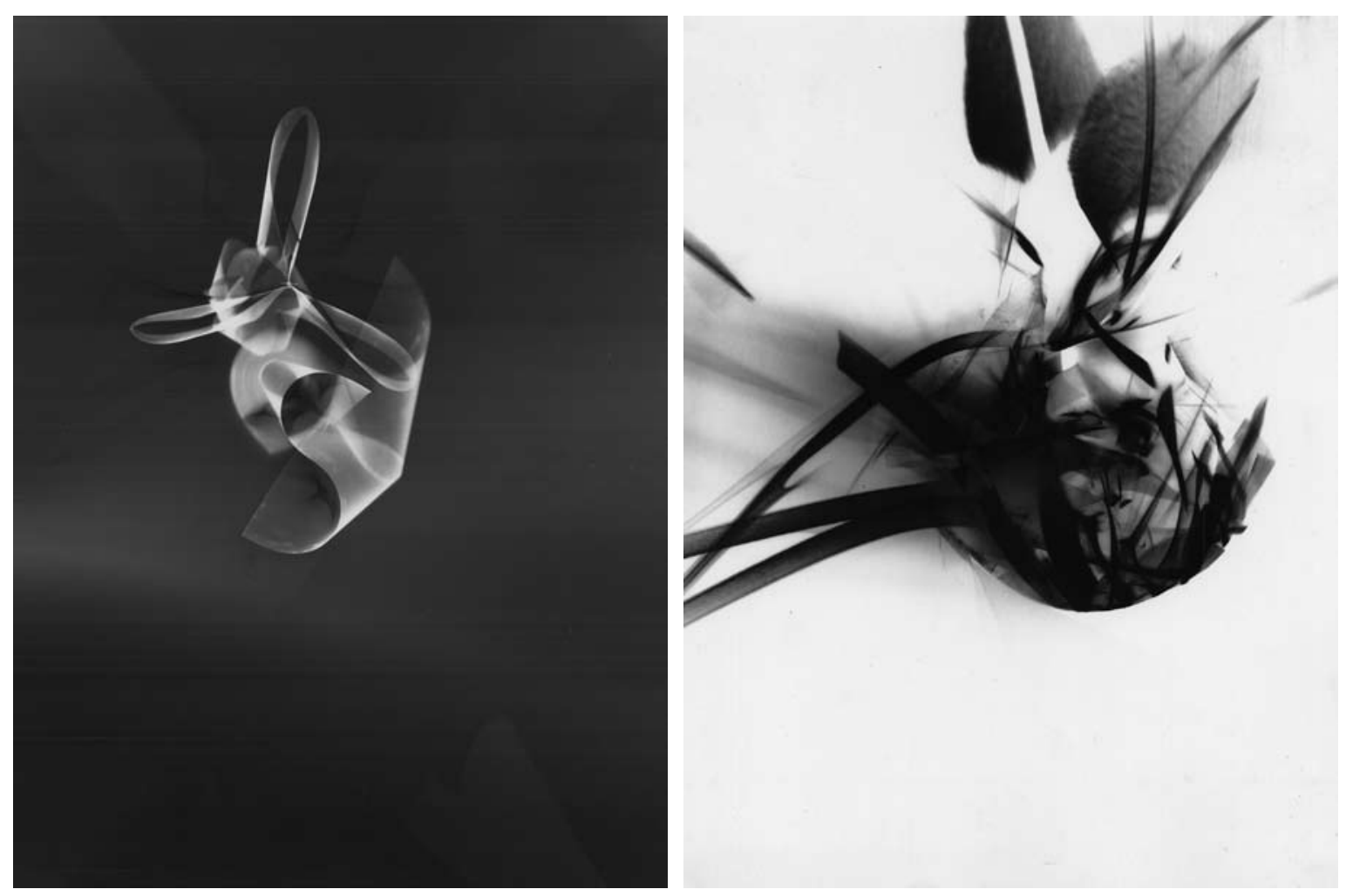
artistic function of expression than with the reproductive function of portrayal" (Kostelanetz, 1970: 51), Moholy-Nagy produced the dynamic presence of the image of light as a material engaging a surface. The two-dimensional plane of the photograph became a surface record presenting the ability to see light transparently, translucently, opaquely and refractively, thereby changing the state of both the light and the object. By actually drawing with light, the photogram, as Moholy-Nagy named this production, reveals a continuous presence and shifts both drawing and photography to a space in between stasis and motion.
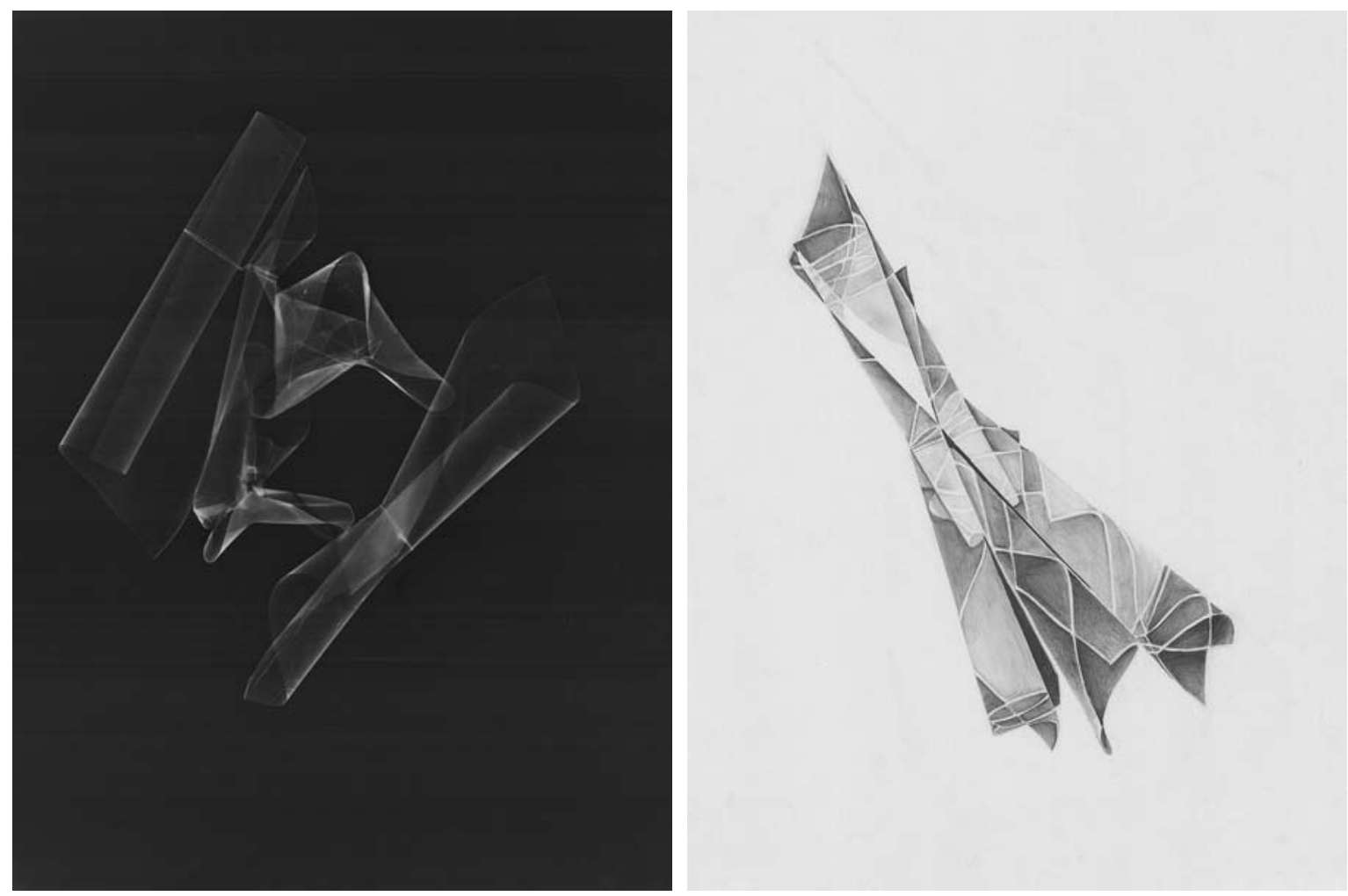

Folded Plane. Photogram: Kate Godfrey

Folded Section. Drawing: Katrina Neirgarth

The examples of such investigations shown here are produced in the setting of the architecture studio, an educational construct that initiates the plastic nature of design as discovery occurring through autonomy natural to open observations and practices. The studies engage the presence and physicality of behaviours of light arrested by a planar surface, and yield artifacts composed by the dynamic spatial relationships of the form and force of light. The artifact's ability to physically produce and make visible what was once invisible in a thing or action stands as a lesson for drawing and announces the opportunity for apprehending correspondences between section and material production. As a direct artifact of light, and the interrelationship of an object placed in tension with light, the photogram is a materially productive tool that registers, activates and transforms both material and phenomenon. 


\section{Re-registration: the frame and photogrammatic space}

In 2000, I witnessed a commercial aired on television by Dodge Motors of the Dodge Chrysler Group LLC that beautifully presented a new sliding side van door feature, and intended to promote its ability to remain open even when parked on a downward slope. The commercial was highly organised to convey relationships in ways just as in the complex spatial prospect of drawing, and, by initiating the multiple depictions of the van in reference to on object seen through it, demonstrated the registrations, re-registrations, and inhabitation of sectional planes.

An axis through the van was imagined as a crucial origin in establishing given relationships, allowing the camera to tightly focus on a goldfish swimming in a fishbowl seen through a picture window in a house directly facing and parallel to the street on which the van was parked. The van itself was not yet in view; only later were the objects through which the axis cut revealed. The fish was the fragment that told the story, and as the fish looked happy, it swam in water that curiously was not level. In order to present the door feature of the van, the ground plane of the frame of reference of the street was recast in an orientation parallel to the horizon. By justifying the frame to a level ground plane, the environment was re-registered, making the axis of the street level, thereby allowing a van with two open heavy side doors to seemingly sit calmly and lightly on a horizontal surface. As the camera began to pull back through the window, and through the open van doors to the elevation of all the objects in view, we ultimately saw the fundamental axis of the ground plane move and shift to its true slope, allowing the water in the fishbowl to seek its own level, and demonstrating what all the fuss was about: the van doors remained open even if parked on a downhill slope. I find the re-framing, extension of reach, depth and breadth, and the resultant re-imagining of the frame with respect to the object it presents to be the strongest visual demonstration of the facts and experiments of the condition of section as sensed and understood in drawing.

The profiles revealed by section and the space between and around the object of study re-situates the total environment and extends the geographic prospect of the frame, making it elastic: a line that shuttles and continually moves. Seeing section as a mobile figural operation based on the re-organisation of frames is a prerequisite for understanding the phenomenon of luminosity as material shape and presence.

The sectional records presented in the plates investigate the instrumentality of light by moving between the technical and the imaginative states of lines and spatial occupation, continually recording, regulating and propagating material illuminations. The instrumentality of drawing acts as a catalyst and makes legible the correspondences of graphic processes of construction and continually constructs and re-constructs interplay within the picture and the line, the gramma and the gramme. As the state of drawing moves between surface and frame, it at times hovers or connects between similar and dissimilar inscriptions of light, concurrently recognising and retrieving, and imagining and projecting. It is in this space that drawing becomes an operation seeking questions as well as rules, and at times simultaneously imposes and derives patterns. Both an act of recognition and an act of invention, the production of sectional drawings from 


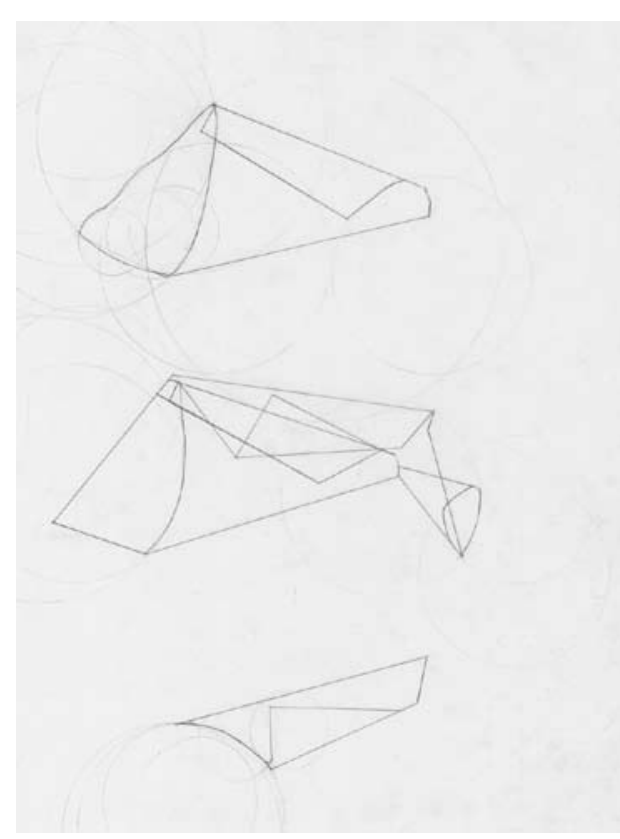

Frame. Drawing: Kate Godfrey

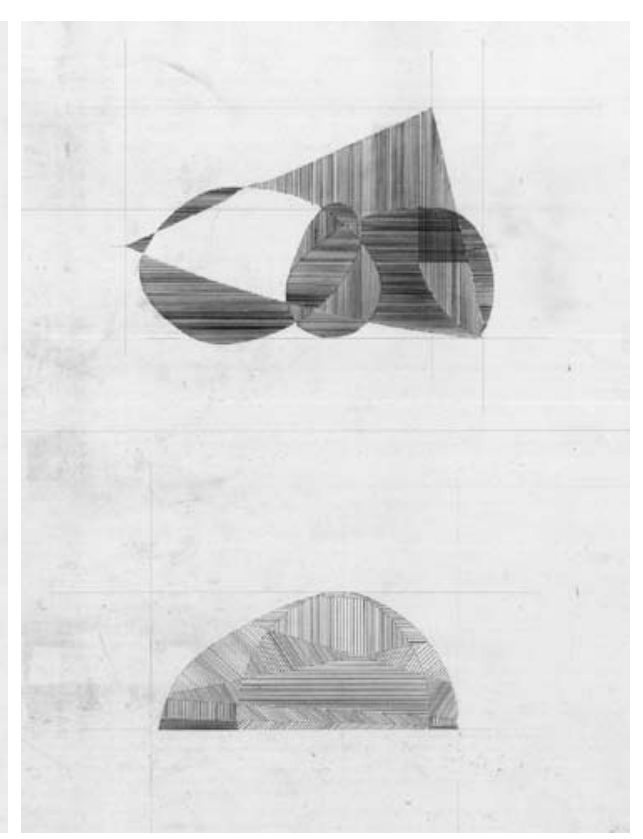

Surface. Drawing: Kate Godfrey

transformative photographic space considers the nature and demonstration of geometric construction as an act of both contingency and specificity, and within a rarefied space of drawing makes shape palpable prior to construction.

\section{The surface: "seeing-in" the vessel of drawing}

Drawing sectionally through photogrammatic space produces an environment that does not attempt to verify the preceding object's original or transformed material dimensions or qualities; instead it seeks to re-recognise material form and potential. Each mark is wholly three-dimensional in its spatial occupation of the plane of the page, and it directly deals with the thickness of shape. Shape is revealed as more than a perimeter, and becomes a surface that can be occupied. A new space of drawing is made where light records the consequence of sectional space prior to material existence. The space is a relic of light. Richard Wollheim recognises this activity as a perceptual state, and imbues this "simultaneous attention" (Wollheim 1980: 213) with the ability to perceive object and medium.

Seeing in is a natural capacity we have - it precedes pictures, though pictures foster it - which allows us when confronted by certain differentiated surfaces, to have experiences that have a dual aspect, or 'twofoldedness': so that, on the one hand, we are aware of the differentiation of the surface, and, on the other hand, we observe something in front of, or behind, something else. (Wollheim 1993: 188)

Drawing is a vessel for both veridical and non-veridical modes of thought, vision and material inquiry. Moving between Wollheim's "seeing-in", or representational seeing of relevant three-dimensional aspects in a surface, and a type of nonveridical imaginative resurrection of what already may exist, the photogram, considered as a basis for drawing, understands the sectional projective action. In this photographic space, drawing studies the transformation of the original 
object, and seeks to materially express both interior and exterior, volume and profile, and to engage the construction of drawings as fields of inquiry. The photographic works are a totality of layers, and like the layering practice of Sinopia, a pigment applied before the final painting of the fresco, the under-drawings are initial markings that become a part of the deep surface of the work.
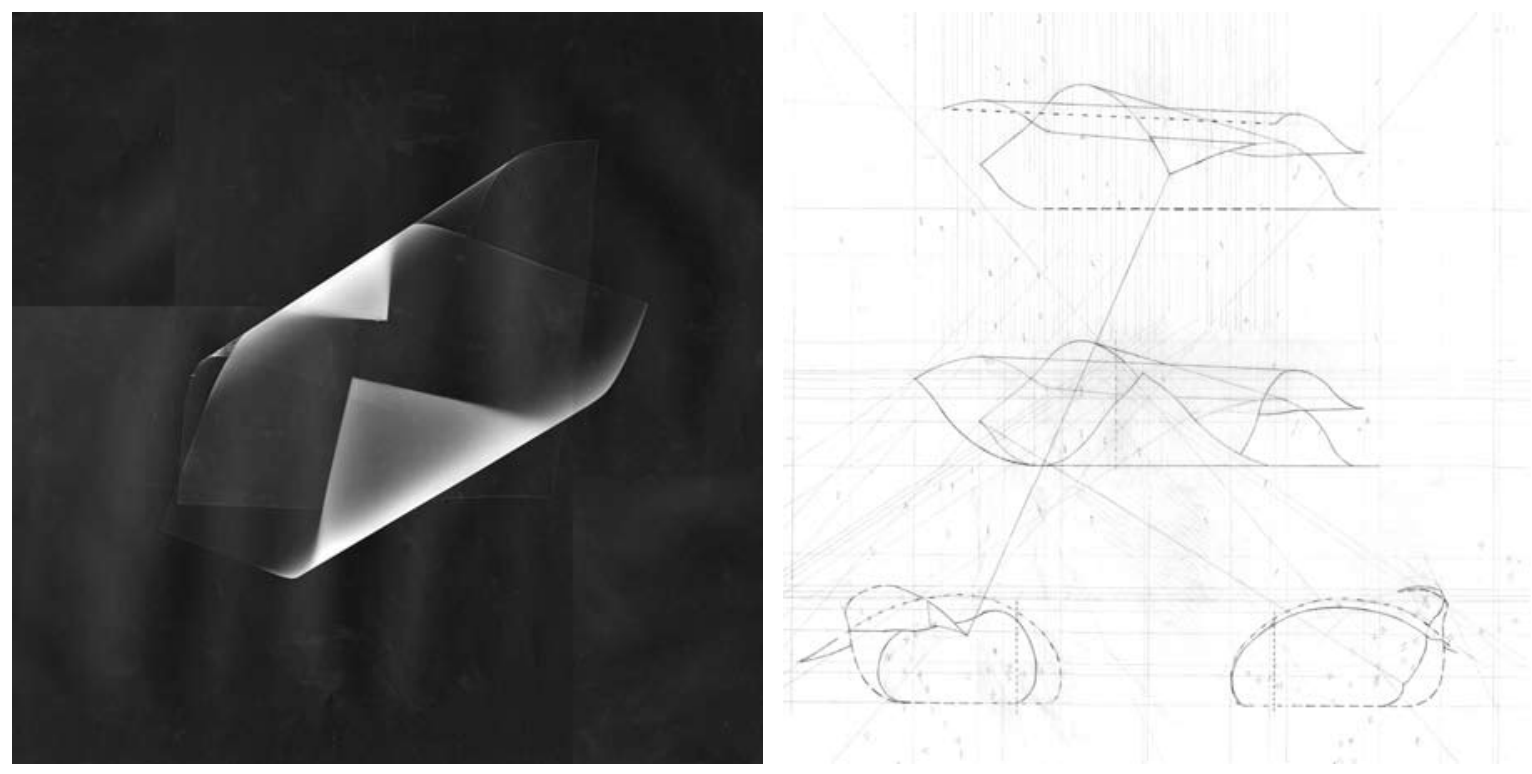

Investigative works produced within the educational setting, these drawings are made with light and graphite, and propose that there are laws found in the acts of forming and the acts of seeing which create new knowledge. Drawing exists in an emergent condition activated by its own means, where the nature and demonstration of form-making determine each drawing's existence, and behaviours both specific and contingent to production manifest an ability for a drawing to build a particular presence. The recognition of movement within the plane, density and dynamism found through material means, celebration of the internal logic of a given material, and the ability of matter to receive and express transformation through action were ideas developed by Theo van Doesburg in the forms, inquiries, and works he termed Plasticism.

The material qualities and formal behaviours in these drawings share the fundamental tenet of Plastic Art, whose problematically-based practices propose that form emerges and is not fixed, having been activated by an origin located solely within the work's own means of production, and by absolute or elemental terms that arose directly out of its own being (van Doesburg 1966: 27). 


\section{"Plastic - the sense of existence which a painting achieves." \\ (Rothko, 2004: 43)}

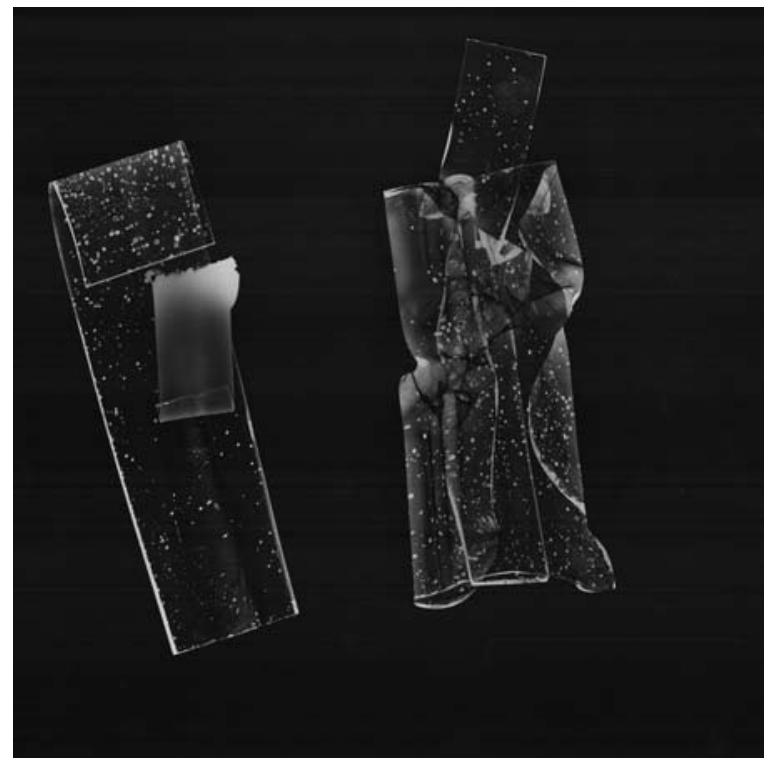

Plasticity. Photogram: Samson Chang

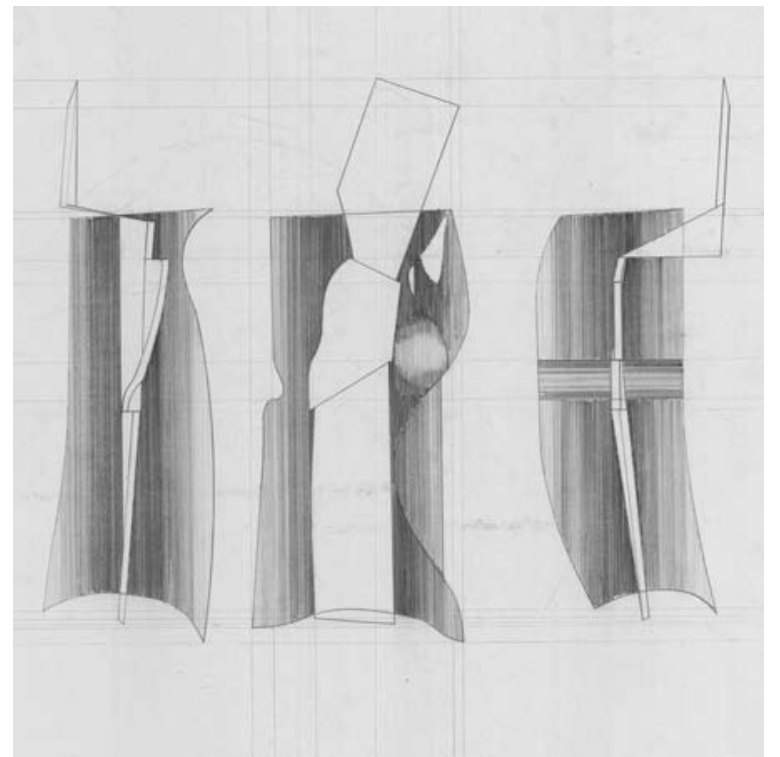

Sovereignty. Drawing: Samson Chang

The author Walker Percy writes that the essential nature of education should be openness (1975: 56-62). This, he believes, is the only condition and environment within which true knowledge may develop. Such true discoveries depend upon the condition of autonomy, and require an environment predicated on the cultivation of the free sovereignty of an individual pursuit. The interrelationship of the idea of form and the act of making require that it is more important for a work to reveal its own nature rather than revel in received ideas. These means of discovery are as critical to the acts of seeing and drawing as they are to education.

\section{Seeing in section: drawing as a relic}

" ... it is just not true that we see pictures in what they depict; rather, we see their depicta in them." (Schier 1986: 199)

In these works, drawing acts as both a carrier to read consequences through the material processes of construction, and a speculative venture that moves the act of drawing closer to the form of poetry. Remnants, traces and pieces of light cast out new frames and net new unified wholes. These may be definite in relation, but temporary in nature, as drawing becomes more like the sensible relics of 


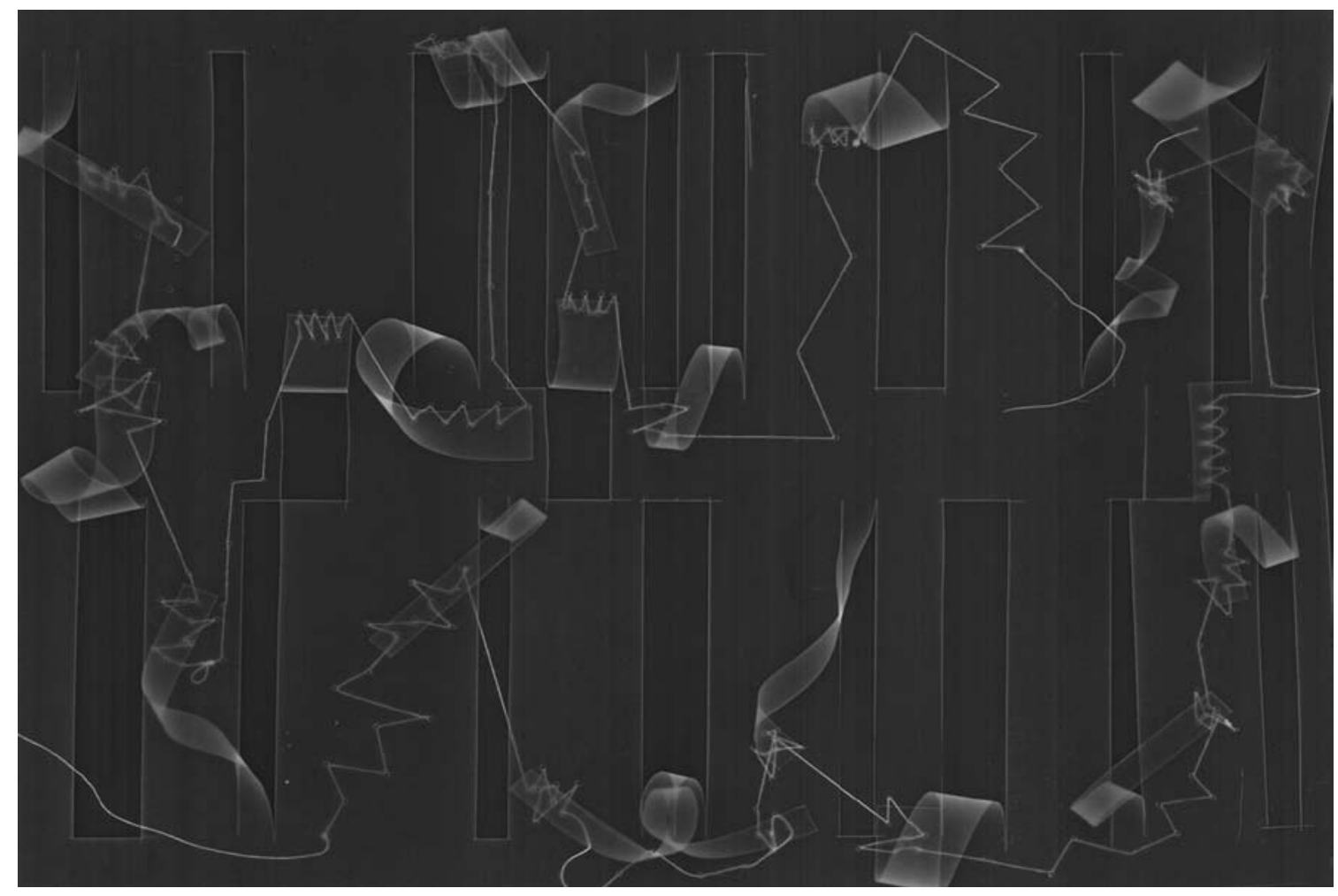

Relic of Light. Photogram: Lisa Cox

light's activity through a surface, a surface whose intangible content is recognisable through traces of form, imagery, and the spirit of material imagination.

\section{References}

Kostelanetz, R. (Ed.). (1970). Moholy-Nagy: An Anthology. New York: Da Capo Press. Percy, W. (1975). Message in a Bottle. New York: Farrar, Straus, and Giroux.

Rothko, M. (2004). The Artist's Reality: Philosophies of Art. New Haven: Yale University Press. Schier, F. (1986). Deeper Into Pictures. Cambridge (UK): Cambridge University Press.

Van Doesburg, T. (1966). Principles of Neo-Plastic Art. New York: New York Graphic Society. Wollheim, R. (1980). Art and Its Objects. Cambridge (UK): Cambridge University Press. Wollheim, R. (1993). The Mind and Its Depths. Cambridge (Mass.): Harvard University Press. 